\title{
8
}
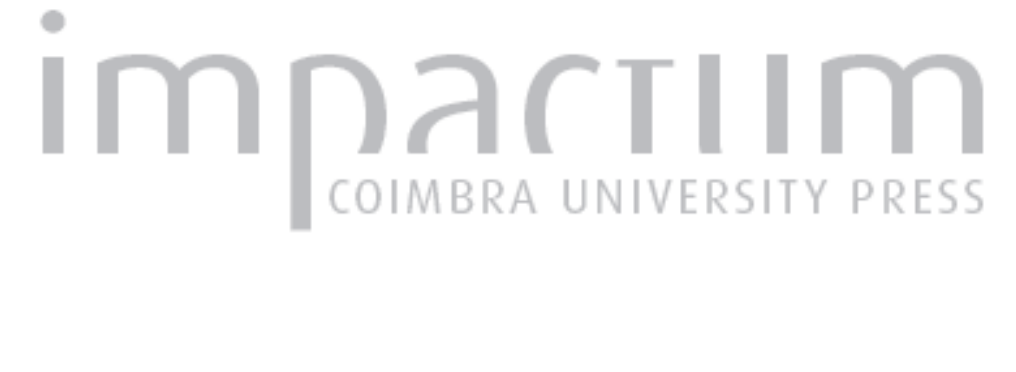

\section{Reviver as guerras Medo-Persas de Heródoto no romance histórico dos inícios do século XX: Helenismo e cultura clássica na época vitoriana}

Autor(es): $\quad$ Santos, Nídia Catorze

Publicado por: Centro de História da Universidade de Lisboa

URL persistente:

URI:http://hdl.handle.net/10316.2/23752

DOI:

DOI:http://dx.doi.org/10.14195/0871-9527_20_23

Accessed : $\quad$ 26-Apr-2023 13:58:46

A navegação consulta e descarregamento dos títulos inseridos nas Bibliotecas Digitais UC Digitalis, UC Pombalina e UC Impactum, pressupõem a aceitação plena e sem reservas dos Termos e Condições de Uso destas Bibliotecas Digitais, disponíveis em https://digitalis.uc.pt/pt-pt/termos.

Conforme exposto nos referidos Termos e Condições de Uso, o descarregamento de títulos de acesso restrito requer uma licença válida de autorização devendo o utilizador aceder ao(s) documento(s) a partir de um endereço de IP da instituição detentora da supramencionada licença.

Ao utilizador é apenas permitido o descarregamento para uso pessoal, pelo que o emprego do(s) título(s) descarregado(s) para outro fim, designadamente comercial, carece de autorização do respetivo autor ou editor da obra.

Na medida em que todas as obras da UC Digitalis se encontram protegidas pelo Código do Direito de Autor e Direitos Conexos e demais legislação aplicável, toda a cópia, parcial ou total, deste documento, nos casos em que é legalmente admitida, deverá conter ou fazer-se acompanhar por este aviso.

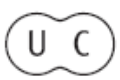




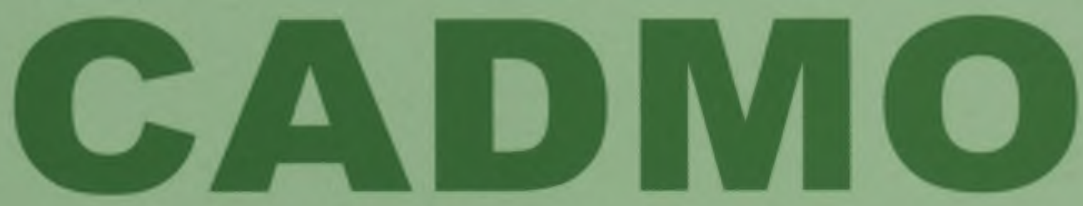

Revista de História Antiga

\author{
Centro de História \\ da Universidade de Lisboa
}

\title{
20
}

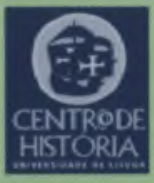

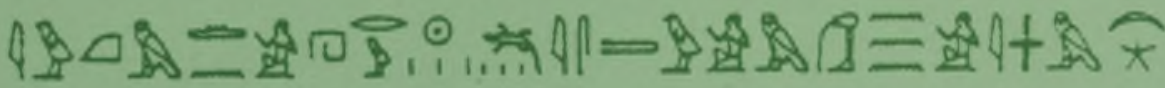

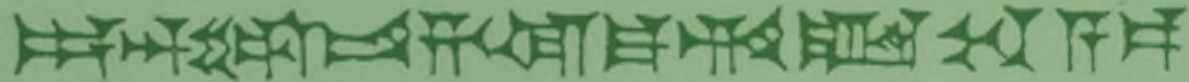

MHNIN AEI $\Delta$ E $\Theta E A ~ \Pi H \Lambda H I A \triangle E \Omega$ 


\title{
REVIVER AS GUERRAS MEDO-PERSAS DE HERÓDOTO NO ROMANCE HISTÓRICO DOS INÍCIOS DO SÉCULO XX: HELENISMO E CULTURA CLÁSSICA NA ÉPOCA VITORIANA
}

\author{
NÍDIA CATORZE SANTOS \\ Universidade de Lisboa \\ nmcsantos@msn.com
}

\section{Resumo}

Com este texto propomo-nos abordar nesta primeira parte, o ambiente cultural em que o romance histórico de tema clássico floresceu no mundo anglo-saxónico do século XIX, integrando-o na educação e na atmosfera cultural do seu tempo. Uma futura segunda parte irá concentrar-se a presença de Heródoto e da herança clássica nas obras de três autores anglo-saxónicos dos inícios do século XX: William Stearns Davis, Caroline Dale Snedeker e John Buchan.

Palavras-chave: Helenismo; Grécia Antiga; romance histórico; recepção da Cultura Clássica.

\section{Abstract}

With this paper we intend to analyse the cultural settings in which the classical theme historical novel flourished in the anglo saxon world of the XIX century, without forgetting to integrate them in the education and cultural atmosphere of his age. A future second part will focus the the early twentieth century reception of Herodotus and the presence of classical world in the works of three english speaking authors: William Stearns Davis, Caroline Dale Snedeker and John Buchan.

Keywords: Hellenism; Ancient Greece; Historical Novel; Classical Receptions. 


\section{O Século XIX e o Romance Histórico}

Com as suas origens na Antiguidade Clássica, o romance, género mais importante do nosso tempo, conheceu um forte impulso durante o Romantismo, época onde o passado histórico assumiu uma relevância sem precedentes. Distingue-se pela permanente transformação, carácter universal e intemporal, onde funde a ficção com o discurso histórico, para apresentar ao leitor, uma ideia da vida e dos costumes da época que retrata, com o objectivo de o entreter.

O primeiro contacto com três obras dos inícios do século $\mathrm{XX}$, A Victor of Salamis: A Tale of the Days of Xerxes, Leonidas, and Themistocles, de William Stearns Davis, The Spartan de Caroline Dale Snedeker, e The Lemnian de John Buchan, levantaram-nos desde logo algumas interrogações devido ao labor académico envolvido na sua composição, assim como a sua difusão entre o público leitor. Poderia o leitor comum, sem grandes noções de Cultura Clássica, acompanhar e apreciar a multiplicidade de referências literárias e mitológicas que perpassam a narrativa a cada página? Ou, pelo contrário, devido às suas características, ocupavam um nicho editorial restrito, dirigido a um público específico? São estas questões a que tentaremos dar resposta nesta primeira parte.

O século XIX ficou marcado por grandes mudanças sociais e económicas, motivadas pelo progresso industrial e científico. Estas foram igualmente acompanhadas por uma mudança nos hábitos de leitura da população, que passou da leitura religiosa para a secular, da colectiva para a individual, e de um número restrito de obras à disposição, para uma leitura efémera, como é o caso de jornais e revistas. Para esta mudança nos hábitos de leitura contribuiu em muito o aumento dos salários e a diminuição dos horários de trabalho, na segunda metade do século, em Inglaterra. Estas alterações permitiram às classes trabalhadoras aceder a uma mercado editorial de livros, jornais e revistas de baixo custo que se encontrava em expansão. Em 1897, um penny possibilitava a aquisição de um volume de Longfellow ou de Arnold, entre outros autores, editados pela colecção Penny Poets de W.T. Steads, facilitando dessa forma o acesso de grande parte da população à leitura, em especial a da classe trabalhadora.

Uma janela preciosa para este universo literário é-nos aberta por Thomas Hardy no seu romance Jude the Obscure (1895), onde nos confronta com o esforço de Jude, o protagonista, canteiro de profissão, para se auto-instruir desde tenra idade, de forma a poder candi- 
datar-se à Universidade de Christminster, e com a sua dificuldade, por vezes extrema, em obter a bibliografia fundamental para as suas leituras. Para tal, lançou-se no estudo do grego e do latim, através das passagens mais simples de Homero, César, Virgílio, Horácio ou do Novo Testamento, socorrendo-se apenas do auxílio umas velhas gramáticas e as edições da Delphin, as mais económicas do seu tempo. Apesar de se sentir mais confiante no latim, estava orgulhoso por ter lido dois livros da llíada e conhecer ainda passos do nono, décimo quarto, décimo oitavo e vigésimo terceiro. As suas leituras estendiam-se ainda a um pouco de Hesíodo e Tucídides, aos primeiros seis livros de Euclides, Padres da Igreja, apesar das dificuldades sentidas com os diferentes dialectos e, ainda à história romana e inglesa. Planeava, mal que se mudasse para a cidade universitária de Christminster, ler os autores que não conseguira encontrar na sua aldeia, entre os quais: Tito Lívio, Tácito, Heródoto, Ésquilo, Sófocles, Aristófanes, Eurípides, Platão, Aristóteles, Lucrécio, Epicteto ou Séneca ${ }^{(1)}$. Os esforços e as leituras de Jude encontram assim eco nos dados recolhidos por algumas bibliotecas à época.

Logo em 1858, a Liverpool Free library verificou que era entre a classe trabalhadora que se praticava uma leitura mais séria, sendo que os livros de História e Literatura foram responsáveis por $40 \%$ dos empréstimos. A Porthmouth Free Public Library apresentou dados semelhantes. Nos anos de 1887-1888, a maioria das requisições, se excluirmos os estudantes, foi realizada por carpinteiros navais e trabaIhadores fabris. Um volume de Aristóteles foi requisitado por um sapateiro, um carpinteiro, dois empregados domésticos, dois negociantes com loja de fazendas, dois serraiheiros, um ourives, um pintor, um pasteleiro, dois carpinteiros navais, um empregado de loja, um ferreiro, um alfaiate e um fiel de armazém. Por seu lado, entre os jovens lojistas e empregados de escritório, predominava o gosto por uma leitura mais leve ${ }^{(2)}$. Perante estes dados, aventuramo-nos a afirmar que quer Heródoto quer os romances históricos inspirados pelas suas Histórias podem ter sido lidos e apreciados por um grupo heterogéneo de leitores, apesar da leitura de romances ser considerada um entretenimento frívolo e encarada durante algum tempo com reservas. Reservas estas que levaram a acérrimos debates sobre a aquisição de obras de ficção pelas primeiras bibliotecas públicas ${ }^{(3)}$, motivados em grande medida pela preocupação sobre a forma como a ciasse trabalhadora usava e abusava da sua literacia crescente. Alguns sectores da sociedade, apesar do sucesso nas vendas e de um dos grandes primeiros-ministros da 
Grã-Bretanha, William Gladstone, como a própria rainha Vitória, serem leitores de romance e um outro ilustre primeiro-ministro, Benjamin Disraeli, ter sido ele próprio um romancista de sucesso, temiam que as bibliotecas incentivassem o ócio e o crime. Este ultimo seria encorajado pela imaginação impressionável dos leitores de romances sensacionalistas de horror gótico ou crime violento, enquanto as esposas descuravam os afazeres domésticos, absorvidas pelas leituras de romances $^{(4)}$. Estas reservas acabaram por se revelar, em grande medida, infundadas.

Entre 1837 e 1901 foram publicados cerca de sessenta mil romances na Grã Bretanha( ${ }^{(5)}$, e a cada ano era necessária uma tiragem mais elevada, de forma a dar resposta à procura dos leitores. Se até à publicação dos romances de Scott este género literário tinha uma tiragem entre 500 e 700 exemplares, Waverley vendeu mil exemplares no espaço de pouco dias e mais dois mil foram vendidos nos três meses seguintes. As novelas seguintes mantiveram esta tendência, com as primeiras edições de Rob Roy (1818) e Ivanhoe (1820) a venderem mais de dez mil cópias cada(6). Nomes como Charles Dickens, George Eliot, as irmãs Brontë, Elizabeth Gaskell, William Makepeace Thackeray, Thomas Hardy, Henry Fielding, Anthony Trollope, Henry James, Jane Austen, Lawrence Sterne, Wilkie Collins, James Fenimore Cooper ou Conan Doyle são, nos dias de hoje, sinónimos do romance anglo-saxónico dos séculos XVIII e XIX. De entre estes, Walter Scott (1771-1832) é justamente aclamado como o criador do romance histórico moderno no continente europeu, que se the rendeu aquando da publicação de Waverley (1814) e Ivanhoe (1820). Ao contrário do que acontecia até então, o romancista escocês afastou a história do estudo da política e do poder, visto que considerava que ela não se reduzia a reis, nobres e generais. Muito pelo contrário. Nas suas obras concentra a narrativa nos grupos marginalizados pela sociedade que ganham desta forma e, pela primeira vez, um protagonismo desconhecido até à época.

A par destes autores de primeiro plano, se assim os podemos denominar, o romance histórico ficou ainda ligado a nomes como John Gibson Lockhart, Edward Bulwer Lytton, Charles Kingsley, Walter Pater, Alfred Church, Cardeal Wiseman, Lew Wallace, entre muitos outros, precursores de autores como Mary Renault, Steven Saylor, Lindsay Davis, Steven Pressfield ou Valerio Massimo Manfredi, que situaram na Antiguidade os seus romances históricos. O sucesso desta temática entre os leitores, em especial pelos romances inspirados pela Grécia 
Antiga é testemunhado pelo volume de títulos publicados no mundo anglo-saxónico entre 1800 e 1950: sensivelmente cerca de 221(7). Nestes, o leitor encontra todos os períodos da história grega, desde os temas mitológicos, à guerra de Tróia, passando pelas Guerras Medo-Persas e Guerra do Peloponeso, até ao Helenismo representado, como não poderia deixar de ser, por Alexandre o Grande e Cleópatra. Esta última, surgindo como o ponto de encontro das três civilizações do Mediterrâneo: Egipto, Grécia e Roma.

Entre estes primeiros romancistas, a mística que rodeava a Roma dos Césares e o seu vasto império foram os temas de eleição. Baseados nos textos clássicos e influenciados, em grande medida, pelas descobertas arqueológicas, que se multiplicavam desde o século XVII, incluíam ainda descrições dos locais e monumentos, para criarem narrativas que tinham como pano de fundo, um ambiente histórico reconstituído, onde as figuras históricas ajudavam à verosimilhança. Foi este o caso de Fabiola do Cardeal Wiseman (1855). A história baseou-se nas informações recolhidas nas investigações que haviam decorrido à época nas catacumbas de Roma e nos santos e mártires do século IV da nossa era, aquando das perseguições dioclecianas. Dois anos antes, Charles Kingsley tinha publicado Hypatia, onde somos confrontados com uma visão muito critica dos monges da Alexandria do século V. Perante o teor anti-católico do romance, a resposta surgiu da pena de John Henry Newman, que se concentrou, por sua vez, nas primeiras conversões na sua Callista: $A$ Tale of the Third Century (1855). Também figuras como o caudilho bretão Caratáco foram fonte de inspiração para autores como G. Whyte-Melville e G. A. Hety, que escreveram, respectivamente, Gladiators (1863) e Beric, The Briton (1893). Em ambas as obras, encontramos associado o heroísmo dos antigos povos britânicos, seus antepassados, com a herança cultural e política de Roma. Também o Cristianismo emergente, envolto numa atmosfera de virtude, coragem e martírio, e a Antiguidade Tardia foram retratados em múltiplos romances históricos. Esta moda foi em grande medida da responsabilidade de Bulwer Lytton, que abordou nos Os Últimos Dias de Pompeia (1834), nos últimos cinco capítulos, a presença do cristianismo, através da conversão de Glauco e lone ${ }^{(8)}$. Por sua vez, o romance histórico norte-americano centrou-se desde o primeiro momento no tema das origens da identidade nacional, abordando os conflitos entre europeus e nativos americanos, ou entre os colonos e a França, Espanha ou Inglaterra. A plantação sulista ou a fronteira ${ }^{(9)}$, em que se retrata quer o território quer os homens e mulheres que 
construíam a nação emergente, em termos idílicos eram igualmente temas populares, apesar do seu teor vincadamente regional. Tal como na Grã-Bretanha, o século XIX ficou marcado por profundas transformações nos Estados Unidos. Através da conquista, tratados ou compra, o país viu o seu território quadruplicar-se, processo que foi acompanhado por um aumento populacional conseguido graças às vagas maciças de imigrantes, das mais variadas nacionalidades e religiões. No entanto, também ele acabou por se render à Antiguidade Clássica. Nathaniel Hawthorne situou o seu Fauno de Mármore (1860) em Roma, protagonizado por dois amantes americanos e um italiano, parecido com o fauno de Praxíteles e que é lançado da rocha Tarpeia para a morte. Todavia, a génese do romance histórico do outro lado do Atlântico tem sido atribuída a Mordecai M. Noah, que publicou em 1822 The Grecian Captive, e a John Howard Payne, autor de Oswaldi of Athens (1831), ainda que o mais famoso romancista seja, sem sombra de dúvida, Lew Wallace, cujo Ben-Hur (1880) se converteu num best-seller que o cinema se encarregou de imortalizar. Já no século XX, destacam-se nomes como George Horton, Like Another Helen (1901); William Stearns Davis, A Victor of Salamis: A Tale of the Days of Xerxes, Leonidas, and Themistocles (1907); Caroline Dale Snedeker The Coward of Termopylae (1911), reeditado no ano seguinte sob o título de The Spartan; John Erskine, The Private Life of Helen of Troy (1925); Thornton Wilder, The Women of Andros (1930); Howard Fast, Spartacus (1952); John Updike, The Centaur (1963); e Gore Vidal, Julian (1964)(10).

\section{Para um país, um bom mapa é o seu primeiro certificado civiliza- cional $^{(11)}$}

Os últimos dois séculos foram fundamentais na construção da geografia e identidade da Grécia, nação que até 1821 - ano da guerra da independência do domínio turco otomano - existiu no imaginário europeu apenas evocação das manifestações textuais, arquitectónicas, arqueológicas e artísticas da Civilização Clássica. Considerada uma idade de ouro, há muito desaparecida, a Grécia transformou-se, todavia, ao longo do século XIX, na alma da identidade helénica, para a esmagadora maioria dos europeus, que em simultâneo viam nela uma Grécia idealizada e eterna, de templos de mármore alvo, das batalhas épicas e da democracia ${ }^{(12)}$. Em suma, o berço da civilização e da cul- 
tura ocidental ${ }^{(13)}$. Efectivamente, nenhum monumento é acompanhado pelo simbolismo que rodeia o Pártenon e a Acrópole de Atenas ${ }^{(14)}$, topoi por excelência do filo helenismo europeu ${ }^{(15)}$. Esta corrente política, ideológica e cultural, com a sua admiração pela civilização clássica, desempenhou um papel fundamental na emergência da jovem nação e na formação das grandes colecções de arte clássica, fomentadas pela ânsia de transplantar a Hélade para os grandes museus do continente europeu.

Os relatos e estudos de viajantes, académicos ${ }^{(16)}$, diplomatas, artistas e turistas, em que descreveram e tentaram identificar e interpretar monumentos e locais famosos, muitos deles conhecidos apenas pelas referências literárias, coincidiram em grande medida com a abertura da Europa, em 1815, após as guerras napoleónicas, aos viajantes ingleses. O nascimento do turismo de massas, cada vez mais comum ao longo deste século, impulsionado pelo desenvolvimento dos transportes e pela disponibilidade proporcionada pelo tempo de lazer ${ }^{(17)}$ foi outro factor de relevo. Este último foi, por sua vez, acompanhado do aparecimento dos guias de viagem, com itinerários e atracções a visitar, que, a par da literatura de viagens, em que se descreviam as paisagens e monumentos ${ }^{(18)}$, instilaram nos leitores e turistas, um sentimento de nostalgia e de continuidade entre o passado e o presente e vice-versa. No entanto, para muitos deles, classicistas incluídos ${ }^{(19)}$, as ruínas acabavam por se revelar uma desilusão quando confrontados com as cercanias e com os edifícios modernos ${ }^{(20)}$.

Neste sentimento de nostalgia e de continuidade, que perdurava ainda nos círculos literários europeus durante a primeira década do século XX, encontramos subjacente uma concepção profundamente hesiódica de história, destinada a repetir-se em solo grego, como o demonstraram algumas das batalhas durante a guerra de independência. Como é natural, num período de renascimento nacional, quando os Gregos se erguiam para expulsarem, uma vez mais, o invasor oriental do solo pátrio, assistiu-se à emergência do imaginário das guerras medo-persas, reforçado no estrangeiro através de imagens que mostravam os soldados gregos com capacetes clássicos, dignos sucessores de Leónidas $^{(21)}$. Nas proximidades das míticas Termópilas, Diakos ${ }^{(22)}$ e 0 Bispo de Anfissa perderam a vida enquanto defendiam, com uma força de setecentos homens, a ponte de Almana de quatro mil soldados turcos. Por sua vez, a umas horas de Queroneia, na estalagem de Gravia, Odisseu e cento e oitenta companheiros enfrentaram trezentos turcos e em Valtetsi, perto de Mantineia, Makromikhalis e Kolokotromis 
à frente de mil soldados puseram em debandada seis mil otomanos. Sob os campos de batalha repousam assim, unidos pelo sono da eternidade, os hoplitas do passado e os patriotas dos tempos modernos ${ }^{(23)}$.

O interesse do público pela Antiguidade e seus monumentos foi também encorajado pelo mercado editorial. Em 1753, Robert Wood publicou, em volumes in folio, ilustrações das ruínas de Palmira e no ano seguinte as de Baalbeck que, por sua vez, inspiraram Robert Adam a publicar em 1764 , as ruínas do palácio de Diocleciano em Split. Estas edições foram seguidas pelos desenhos dos principais monumentos de Atenas, da autoria de James Stuart e Nicholas Revett, em $1787^{(24)}$. Nas décadas seguintes, graças aos avanços tecnológicos, as edições ilustradas assim como as de textos clássicos de qualidade vulgarizaram-se e foram-se tornando cada vez mais acessíveis. A Teubner passou a disponibilizar textos fiáveis, ainda que com notas em latim, a partir de 1828, sendo imitada nas décadas seguintes por H.G. Bohn, que lançou entre 1848 e 1913 cento e dezasseis volumes de traduções, ou por William Blackwood que editou a colecção Ancient Classics for English Readers, entre 1870 e 1932, que constituía uma introdução aos textos e autores, com passos traduzidos e sumários das obras publicadas. Estas revelaram-se essenciais para a audiência feminina ter acesso aos autores greco-latinos, ainda que algumas mulheres pudessem apreciá-los no original, como foi o caso de George Eliot, que aprendeu grego sozinha, ou Elizabeth Barrett Browning, cuja fluência em grego the permitiu ler Homero no original. Mas estas eram claramente excepções ao seu tempo ${ }^{(25)}$, como nos é confirmado por Sue Bridehead, prima de Jude, o jovem auto-didata. Como a própria admite sem rodeios, não sabia nem grego nem latim, apesear de conhecer a gramática de ambas as línguas. O seu contacto com os clássicos chegava-lhe através de traduções onde incluiu nomes como Catulo, Marcial, Juvenal, ou Luciano. Através de Edward Gibson, o companheiro de mesa-de-cabeceira estudava o reinado de Juliano o Apóstata, mas a sua lista de leituras não ficava por aqui e ainda se estendia a Boccaccio, Lempriére, Sterne, Defoe, Smollett, Fielding, Shakespeare e à Bíblia. Esta enumeração leva Jude a reconhecer, resignado, que ela tinha lido mais do que ele l(26). $^{(2)}$

Desde a Renascença que a educação se centrou no ensino do Grego e do Latim e da Civilização Clássica, de modo a preparar os jovens para a entrada nas melhores escolas, universidades, no exercício do direito, funções eclesiásticas ou funcionalismo público, através de disciplinas como História, Retórica e Eloquência. As mulheres 
foram, todavia, dela excluídas, assim como os jovens de meios desfavorecidos. Reservada à elite, a educação clássica era, de facto, o elemento distinto de um cavalheiro de posição social. Na Grã-Bretanha como nos Estados Unidos, muitas mulheres insatisfeitas com a educação que Ihes era ministrada, nas escolas para raparigas ou em casa por tutores e governantas e, que raramente incluía o ensino do Grego e do Latim, optaram por se embrenhar no estudo solitário da sua disciplina de eleição. Recorriam aos livros utilizados pelos seus irmãos e assistiam por vezes às suas aulas que complementavam com artigos e recensões de jornais, além de obras de referência como o Classical Dictionary de Lamprièré (1788), léxicos e as jàs referidas traduções. Este estudo era todavia, mal visto pela sociedade do seu tempo e as estudantes viam-se na contingência de os ocultar, conscientes do velho adágio que profetizava que o latim e o celibato andavam de mãos dadas. Esta situação principiou a alterar-se durante a segunda metade do século XIX, quando cada vez mais mulheres começaram a chegar às universidades femininas americanas, que começaram finalmente a oferecer-Ihes uma educação clássica que rivalizava com a que era ministrada nas suas congéneres masculinas. Muito influenciados pelo Romantismo Germânico e pela relevância que este atribuía aos ideais estéticos e espirituais da Grécia Antiga, os curricula norte americanos impuseram, a partir de 1820 , o estudo intensivo da literatura e arte gregas, que abrangiam autores como Homero, tragediógrafos ou a oratória de Demóstenes ${ }^{(27)}$.

\section{Conclusão}

Esta pequena introdução a um tema tão vasto pretendeu apenas compreender o ambiente cultural e académico que impulsionou a escrita de romances históricos durante o século XIX e inícios do XX. Apesar dos entraves à educação que alguns sectores da sociedade sofreram, como foi o caso das raparigas e dos rapazes de condição mais humilde, a leitura de obras literárias, inclusive greco-latinas, encontrava-se disseminada na sociedade, apesar de a educação clássica ser apanágio de uma pequena elite. O grande público mostrava-se ávido de boas leituras, qualquer que fosse o género. Não nos devemos por isso espantar com a qualidade de alguns destes romances, que a par de um ambiente histórico reconstituído, ofereciam ainda aos seus leitores descrições típicas da literatura de viagens e uma multipli- 
cidade de referências culturais, mitológicas e geográficas. $E$, ao contrário do que poderíamos pensar, os leitores dos séculos XIX e XX, homens e mulheres estavam mais que habilitados na sua descodificação.

\section{Notas}

(1) Thomas Hardy, Jude the Obscure, Wordsworth Classics, 1995, 20-29.

(2) ROSE, 2002, 37.

(3) Entre os romancistas disponíveis nos catálogos, a maioria dos quais são ainda facilmente reconhecidos pelos leitores da actualidade, encontramos Mary Elizabeth Brandon, Walter Scott, Mrs. Henry Wood, Charles Dickens, Edward Bulwer Lytton, Anthony Trollope, R. M. Ballantyne, Margareth Oliphant, Wilkie Collins, Charlotte Younge, James Payn,. Harrison Ainsworth, Jules Verne, Walter Besant, William Black, Ouida, H. Rider Haggard, R.D. Blackmore, Robert Louis Stevenson, Mark Twain e Rhoda Broughton (ROSE, 2002, 39).

(4) BRANTLINGER, THESING, 2002, 1-2, 4, 37.

(5) APUD BRANTLINGER, THESING, 2002, 1

(6) MAYS, 2002, 12.

(7) BEALL, 1967, 53-66

(8) VANCE, 2007, 94-95.

(9) No romance de fronteira, onde se identifica o povo norte-americano como anglo-saxónico, encontramos uma duplicidade na construção dos nativos americanos, os nobres selvagens de Fenimore Cooper. Se a sua cultura e estilo de vida eram considerados atributos distintivos do carácter e espírito indomável americano, que the permitia enfrentar as situaçōes mais delicadas, a sua personificação como selvagens incivilizados perdurou até ao século passado (CRANE, 2007, 390, 451).

(10) BRIGGS, 2007, 293.

(11) FOUGÈRES, 1910, 110.

(12) Esta visão idealizada foi sublinhada por um romancista grego da época, ao colocar Iondrinos comuns perante um turista grego de visita à cidade: "You are both spot on... or rather neither of you is correct, because my parents are of Gallo-Italian origin, but I was born in Turkey and am Greek." "Goddam!" they cried. "We have never before suffered such a miscalculation in a bet that we have placed." Another gentleman, having himself run over to our gathering that he might learn the outcome of the bet, and having discovered that I was in fact Greek, shouted "Greek? An ancient one or a modern one?" This question did not appear to me to be lacking in mirth. "If you are suggesting, my dear sir," I said to him, "Homer, Demosthenes and Thucydides, these men, even though they were contemporaries of the Greek Gods, were nonetheless by some stroke of bad luck mere mortals and left us long ago; the ancients gave way to others, and those to others still; but the country remains the same." "You are right," he replied; "what a creature I am! What I should have asked you was whether you speak the ancient or the modern tongue. I am very fond of the Greeks, and enjoy hearing of their acts of gallantry. It is because you are the first Greek that I have seen that this anachronism has befallen me" (APUD TZIOVAS, 2001, 190). 
(13) Nas palavras de Shelley, no Prefácio a Hellas (1821): "We are all Greeks, our laws, our literature, our religion, our arts have their roots in Greece".

(14) "There is only one place, not two, where perfection exists: it is this place here. I never imagined that there existed anything like it. What I encountered before me was the very ideal incarnated on Pentelic marble. Until this time I believed that perfection was not of this world (...) something that could only have occurred once, that had never appeared before, that would never be seen again, whose impression would be preserved eternally. I mean to say: it is a type of eternal beauty without local or nationalist colour ... When I saw the Acropolis I accepted the revelation of the divine... Then the entire world seemed barbarous to me» (Renan, 1865, APUD TZIOVAS, 2001, 197).

«For a long time I stayed away from the Acropolis. It daunted me, that somber rock. I preferred to wander in the modern city, imperfect, blaring. The weight and moment of those worked stones promised to make the business of seeing them a complicated one. So much converges there. It's what we've rescued from madness. Beauty, dignity, order, proportion. There are obligations attached to such a visit. (...) It looms. It's so powerfully there. It almost forces us to ignore it. Or at least to resist it" (Don DeLillo 1987:3-5, APUD TZIOVAS, 2001, 198).

(15) Estes mesmos monumentos eram encarados de forma ambígua pelos próprios gregos. Testemunhos silenciosos de outro tempo e civilização, eram reverenciados pela sua beleza e perícia dos artificies que os construíram, mas em simultâneo, foram encarados pela Igreja Ortodoxa como símbolos de uma época idolatra, e permitiram-lhe estabelecer uma dicotomia entre os gregos antigos e os modernos. Considerava estes últimos como piedosos cristãos ortodoxos ao contrário dos antepassados heréticos, ímpios ou ateus. Numa época em que o tempo era indissociável da religião, o domínio turco era assim visto pela população cristã como um castigo pelos pecados do passado (HAMILAKIS, 2007, 65, 67 n. 3).

(16) De assinalar todavia que alguns dos maiores vultos do Helenismo germânico, como Winlckelmann, curiosamente, nunca visitaram o país.

(17) YOUNGS, s.d., 6

(18) Esta intemporalidade encontra-se bem patente no guia Seeing Europe with Famous Authors, uma publicação datada de 1914, que conjuga textos de viajantes contemporâneos com os relatos de Pausânias com fotografias dos monumentos, para apresentar a Grécia, entre outros destinos, ao público leitor. A Atenas e à sua Acrópole são dedicadas sete páginas e é sem surpresas que o início da descrição da cidade nos evoca o romance de Aquiles Tácio, Os Amores de Leucipe e Clitofonte (1.1.1-3): “There is probably no more exciting voyage, to any educated man, than the approach to Athens from the sea. Every promontory, every island, every bay, has its history. If he knows the map of Greece, he needs no guide-book or guide to distract him; if he does not, he needs little Greek to ask of anyone near him the name of this or that object; and the mere names are sufficient to stir up all his classical recollections (...). [The Peiraeus] is still, as in Plato's day, "the haunt of sailors, where good manners are unknown." But when we had escaped the turmoil, and were seated silently on the way to Athens, almost along the very road of classical days, all our classical notions, which had been scared away by vulgar bargaining and protesting, regained their sway. We had sailed in through the narrow passage where almost every great Greek that ever lived had some time passed; now we went along the line, hardly less certain, which had seen all these great ones going to and fro between the city and the port (...). The present road is shaded with great silver poplars, and plane trees, and the moon had set, so that our approach to Athens was even more mysterious than our approach to the Peiraeus. At last we entered the unpretending ill-built streets at the west of Athens.... (...) And there (...) stood the rock which of all rocks in the world's 
history has done most for literature and art - the rock which poets, and orators, and architects, and historians have ever glorified, and can not stay their praise - which is ever new and ever old, ever fresh in its decay, ever perfect in its ruin, ever living in its death the Acropolis of Athens. (....) I suppose there can be no doubt whatever that the ruins on the Acropolis of Athens are the most remarkable in the world. (...) There is no ruin all the world over which combines so much striking beauty, so distinct a type, so vast a volume of history, so great a pageant of immortal memories. There is, in fact, no building on earth which can sustain the burden of such greatness, and so the first visit to the Acropolis is and must be disappointing. When the traveler reflects how all the Old World's culture culminated in Greece - all Greece in Athens - all Athens in its Acropolis - all the Acropolis in the Parthenon - so much crowds upon the mind confusedly that we look for some enduring monument whereupon we can fasten our thoughts, and from which we can pass as from a visible starting-point into all this history and all this greatness (...). In its great day, and even as Pausanias saw it, the Acropolis was covered with statues, as well as with shrines. It was not merely an Holy of Holies in religion; it was also a palace and museum of art. At every step and turn the traveler met new objects of interest. There were archaic specimens, chiefly interesting to the antiquarian and the devotee; there were the great masterpieces which were the joint admiration of the artist and the vulgar" (MAHAFFY, 1914, 112-119).

(19) «Like every student, I was deeply impressed when I found myself standing under the shadow of the Parthenon. But this feeling did not last. It gave way to an oppressive doubt: There was only one Hellas, and she is gone and will not come again (..)" (apud TZIOVAS, 2001, 195).

(20) "Still, it was possible to see the Parthenon, as white as though it had been carved from salt, glittering and elegant, and towering over the dismal city of congested traffic and badly-built tenements. Apart from what remained of its ancient ruins, and the treasures in its museums, Athens had to be one of the ugliest cities on earth, indeed ugly and deranged enough to be used as the setting for yet another variation on the Heart of Darkness theme, perhaps to be called Acropolis Nown (apud TZIOVAS, 2001, 197-198).

(21) Em simultâneo, recuperou-se também a onomástica clássica, através de nomes como Leónidas, Temistocles ou Aristides que relegaram para segundo plano nomes tradicionais como Yannis, Petros ou Kostas (HAMILAKIS, 2007, 78).

(22) Atanásio Diakos (1788-1821) foi um comandante militar durante a Guerra da Independência.

(23) HOMOLLE, 1910, 17, 38-9; FOUGĖRES, 1910, 109.

(24) JENKYNS, 2007, 274-275.

(25) VANCE, 2007, 95-96

(26) Thomas Hardy, Jude the Obscure, Wordsworth Classics, 1995, pp.84-133.

(27) FISKE, 2008, 5, WINTERER, 2001, 70-75, 85).

\section{Bibliografia:}

ARDIVSSON, S., (2006), Aryan Idols: Indo European Mythology. An Ideology and Science. University of Chicago Press, Chicago and London.

BEALL, H.S., (1967), Historical Fiction on Classical Themes: Revised List, 1967, CW, 61.2, $53-66$. 
BRIGGS, W., (2007), United States, in: Graig Kallendorf (ed.), A Companion to the Classical Tradition, Blackwell Publishing, Malden, MA, 279-294.

BULWER LYTTON, E., (1903), The Last Days of Pompeii, Charles Scribner's Sons, New York.

CRANE, G. (2007), The Cambridge Introduction to the Nineteenth Century American Novel, Cambridge University Press, Cambridge.

FISKE, S., (2008), Heretical Hellenism: Women Writers, Ancient Greece, and the Victorian Popular Imagination, Ohio University Press, Athens.

FOUGĖRES, G., (1910), Pictoresque Greece: the Country and the People, in: G. F. Abbott (Ed.), Greece in evolution. Studies prepared under the auspices of the French League for the Defence of the rights of Hellenism, Wessels \& Bissell, New York, 97128.

FUCHS, B., (2004), Romance, Routledge, New York and London.

HAMNETT, B., (2006), Fictitious Histories: The Dilemma of Fact and Imagination in the Nineteenth-Century Historical Novel, EHQ, 36, 31-60.

HAMILAKIS, Y., (2007), The Nation and Its Ruins. Antiquity, Archaeology and Nation Imagination in Greece, Oxford University Press, Oxford.

HARRISON, T., (2008) Respectable in its Ruins: Achaemenid Persia, Ancient and Modern, in: Lorna Hardwick, Christopher Stray (ed.) A Companion to Classical Receptions, Blackwell Publishing, Malden, MA, 50-61.

HOMOLLE, T., (1910), Why We Love Greece, in: G. F. Abbott (Ed.), Greece in evolution. Studies prepared under the auspices of the French League for the Defence of the rights of Hellenism, Wessels \& Bissell, New York, 13-41.

JENKYNS, R., (2007), United Kingdom, in: Graig Kallendorf (ed.), A Companion to the Classical Tradition, Blackwell Publishing, Malden, MA, 265-278.

MAHAFFY, J. P, (1914), Arriving in Athens: The Acropolis, in: Francis W. Halsey (ed.) Seeing Europe with Famous Authors, Vol. VIII: Italy, Sicily and Greece, Part Two, FUNK \& WACNALLS COMPANY, New York and London, 112-119.

MALLORY, J. P., (1991), In Search of the Indo-Europeans. Language, Archaeology and Myth, Thames and Hudson, London.

ROSE, J., (2002), Education, Literacy and the Victorian Reader, in: P. Brantlinger, W. B. Tthesing, (ed), A Companion to the Victorian Novel, Blackwell Publishing, Malden, MA, 31-47.

SAUNDERS, C., (2004), A Companion to Romance: From Classical to Contemporary, Blackwell Publishing, Malden, MA.

STONEBANKS, C. D., (2008), Spartan Superhunks and Persian Monsters. Responding to Truth and Identity as Determined by Hollywood, Studies in Simbolic Interaction, 31, 207-221.

TZIOVAS, D., (2001), Beyond the Acropolis: Rethinking Neohellenism, JMGS, 19, 189-220.

VANCE, N., (2007), Victorian, in: Graig Kallendorf (ed.), A Companion to the Classical Tradition, Blackwell Publishing, Malden, MA, 87-100.

WINTERER, C., (2001), Victorian Antigone: Classicism and Women's Education in America, 1840-1900, AQ, 53, 1, 70-93.

YOUNGS T., (s.d.), Travel Writing in the Nineteenth Century: Filling the Blanks Spaces, Antley Press, London and New York. 